\title{
Study Site Oversight Status Review Board Process Date
}

National Cancer Institute

\section{Source}

National Cancer Institute. Study Site Oversight Status Review Board Process Date. NCI

Thesaurus. Code C94145.

The date (and time) on which the Institutional Review Board (IRB) determined the status of this study protocol for execution at this site. 